\title{
SEGURANÇA NACIONAL E SEGURANÇA PÚBLICA NA CONSTITUIÇÃO DE 1988
}

\author{
ÁlVARO LAZZARINI*
}

\begin{abstract}
1. Consideraçōes iniciais. 2. Segurança Nacional e Segurança Pública na Constituição da República. 3. Responsabilidade de cada um dos Poderes da República na defesa do Estado de Direito. 4. Segurança Pública e o aperfeiçoamento da Polícia no Brasil. 5. Conclusão.
\end{abstract}

\section{Consideraçōes iniciais}

Se a segurança nacional volta-se para a garantia da nação como um todo, sendo a ordem e a tranqüilidade gerais exigências do mais alto valor para a realização das atividades nacionais que conduzem ao bem comum ', não se pode deixar de considerar que a temática da ordem pública, em especial no que diz respeito à segurança pública, tem íntimo relacionamento com a mesma segurança nacional, porque assegurar a boa ordem é assegurar a tranquiilidade pública, a segurança pública e a salubridade pública, e nada mais do que isso ${ }^{2}$.

Lembro, como o fiz em anterior palestra que proferi na Escola Superior de Guerra ${ }^{3}$, e à vista do seu Manual Básico de 1993, que "A Expressão Psicossocial do Poder Nacional estuda o Homem, as suas relações em sociedade e o produto dessas relações, vale dizer, ocupa-se dos fenômenos sociais, culturais e psicológicos

1 ESCOLA SUPERIOR DE GUERRA, Manual Básico, 1993, Rio de Janeiro, p. 208.

2 ROLLAND, Louis. Précis de droit administratif. $9^{\mathrm{a}}$ ed., 1947, Librarie Dalloz, Paris, França, p. 399.

3 LAZZARINI, Álvaro. Violência e Segurança-Aspectos do Conflito Social Urbano, Exposiçāo em Painel para os Cursos de Altos Estudos de Política e Estratégia e de Altos Estudos de Política e Estratégica Militares da Escola Superior de Guerra, Rio de Janeiro-RJ, 04 de agosto de 1995, revista "A Força Policial", Polícia Militar do Estado de São Paulo, Ano 1995, abril/maio/junho, n. 6, p. 13-49.

* Desembargador do Tribunal de Justiça do Estado de São Paulo, Professor de Direito Administrativo na Escola Paulista da Magistratura e na Academia de Polícia Militar do Barro Branco, Membro do Instituto dos Advogados de Sāo Paulo. do Instituto Pimenta Bueno - Associação Brasileira dos Constitucionalistas e de "IAPC - The International Association of Chiefs of Police" (USA)

R. Dir. Adm.,

Rio de Janeiro, 213: 11-21.

jul./set. 1998 
na cena nacional. que não se enquadram nas demais expressões do poder. Assim, alcança as questões históricas, a ciência e a tecnologia, a vida espiritual e tudo mais que diga respeito ao Homem e sua organização social. Deve. assim, refletir uma população hígida, de padrões culturais elevados, com suas necessidades básicas satisfeitas e consequientemente com capacidade de atuar em termos de opinião pública, conforme antiga, mas atual lição da Escola Superior de Guerra-ESG", no seu Manual Básico de 1975.

Bem por isso a segurança pública tem papel preponderante na realização da segurança nacional, porque, é uma necessidade básica de qualquer pessoa a de sentir-se com segurança e bem-estar. Seguro, o homem pode trabalhar melhor, implicando a ordem, no progresso do Estado.

\section{Segurança Nacional e Segurança Pública na Constituição da República}

O Constituinte de 1988 evitou referir-se à segurança nacional por motivos ideológicos e preconceituosos. Referiu-se, porém, a ela como examinarei logo mais e, pelo menos, usou a locução segurança nacional no artigo 173, caput, da Constituição da República.

Ney Prado, aliás, isso tinha detectado por ocasião dos trabalhos da denominada "Comissão dos Notáveis", afirmando que as Forças Armadas vinham sendo alvo favorito de preconceitos enquanto instituições militares, e não os seus eventuais chefes, como as responsáveis pelos regimes autoritários, acrescentando que “ $\mathrm{O}$ preconceito contra militares se apresenta de várias maneiras: aberta, veladamente e até grotescamente. A má vontade e o preconceito com relação aos militares assumiram aspectos inusitados. Não sendo possível 'puni-los', objetivamente, muitos trataram de fazê-lo semanticamente. Assim, expressões tecnicamente consagradas como segurança nacional, ordem pública e medidas de emergência, foram proscritas e substituídas por outras, como defesa do Estado, da sociedade civil e instituições democráticas, paz ou tranqüilidade pública e estado de alarme, com perda evidente, de rigor técnico e indesculpável descaso com a boa doutrina que lhe confere tradicional embasamento." 4

Pela Assembléia Nacional Constituinte, o tema, igualmente, foi tratado de maneira emocional, sob o espectro da Lei de Segurança Nacional que acabou influenciando politicamente o texto constitucional em prejuízo do lado técnico conceitual.

No Título V da Constituição da República, nos seus artigos 136 a 144, onde se aborda a ordem política e a ordem pública, preferiu-se adotar a denominação de Defesa Nacional, em consonância com o Conselho de Defesa Nacional previsto no seu artigo 91, órgão consultivo para assuntos de soberania nacional e defesa do Estado Democrático, aquele voltado à segurança externa contra agressão estrangeira,

4 PRADO. Ney. Os Notáveis Erros dos Notáveis (da Comissāo provisória de Estudos Constitucionais), 1 $^{\mathbf{a}}$ ed.. 1987, Editora Forense. Rio de Janeiro. p. 23. 
este voltado à segurança interna. contra a implantação de um estado tirânico que venha a violentar as suas cláusulas pétreas do artigo $60 . \S 4^{\text {ㅇ. }}$.

Estes, assim, os princípios constitucionais vigentes do nosso Estado Democrático, como idealizados pelo Constituinte de $1988 \mathrm{e}$, portanto, os referenciais da segurança interna e, por via de consequiência, da defesa interna, ambas também abolidas da Carta de 1988, mas que conceitualmente continuam a existir.

A mesma Carta, porém, curiosamente, veio a tratar da segurança nacional, usando a expressão no seu artigo 173, integrado ao seu Título VII, isto é, quando cuida "Da Ordem Econômica e Financeira", no que entendo que a segurança nacional se refere à soberania nacional no sentido de proteção das áreas econômicas, cuja reserva deve ficar a cargo do Estado como garantia da soberania da nação brasileira, impedindo que caiam em mãos de particulares que poderiam repassá-las a estrangeiros, não existindo aí o enfoque da ordem política ou da ordem pública, mas essencialmente enfoque da ordem econômica, embora todos os planos da ordem devam se integrar de modo harmônico.

O fato de a Constituição da República falar em Defesa Nacional quando trata assuntos da ordem política e da ordem pública não significa que a Segurança nacional inexista nesses planos, porque, os conceitos de Segurança e de Defesa, em qualquer plano, embora distintos, são indissociáveis: a Defesa existe em prol da segurança. São, portanto, o conjunto de medidas concretas que visam proporcionar um estado abstrato de segurança.

Ao abordar a Defesa Nacional a Constituição da República, bem por isso e implicitamente, abordou a temática da Segurança Nacional, e penso que o Brasil está maduro politicamente - maduro suficientemente - para temer distorções conceituais que não resistiriam aos princípios do Estado Democrático de Direito firmado na Carta de 1988.

Tenha-se, aliás, presente que, mesmo ao tempo do denominado "Regime Militar de 1964", como o atesta Manoel Gonçalves Ferreira Filho, "Para o STF, segurança nacional, na Constituição brasileira, tem extensão menor do que na doutrina da ESG. Disse-o o Min. Aliomar Baleeiro no REC. Extr. n. 62.731, afirmando que 'segurança nacional envolve toda matéria pertinente à defesa da integridade do território, independência, sobrevivência e paz do País, suas instituições e valores materiais e morais contra ameaças externas e internas, seja elas atuais e imediatas ou ainda em estado potencial, próximo ou remoto' (DOU, 28 jun. 1968, p. 2.460)." 5

Desse sentido, aliás, não pode fugir o conceito atual da Escola Superior de Guerra no sentido de que "Segurança Nacional é, para a nação, a garantia, relativa, de que seus objetivos permanentes estão sendo alcançados e preservados, face à sua capacidade, atual e potencial, de superar quaisquer ameaças a esses objetivos"6.

Minha conclusão, assim, é de que a Segurança Nacional está expressa na Constituição da República quando se trata da Ordem Econômica e implícita nos planos da Ordem Política e da Ordem Pública, quando se fala em Defesa Nacional.

5 FERREIRA FILHO, Manoel Gonçalves. Segurança Nacional, verbete de Enciclopédia Saraiva do Direito, v. 67. Edição Saraiva, São Paulo, p. 293-297.

6 ESCOLA SUPERIOR DE GUERRA, Manual Básico, 1993, Rio de Janeiro, p. 208. 
No que se refere à Segurança Pública, como o adverte Manoel Gonçalves Ferreira Filho ao comentar o artigo 144 da Constituição da República, integrado ao seu Capítulo III do Título V - Da Defesa do Estado e das Instituições Democráticas - "O direito anterior não continha norma ou capítulo equivalente. Que é, pois, segurança pública? Os juristas - o ilustre constitucionalista brasileiro responde costumam discutir eruditamente os conceitos de 'segurança pública', 'ordem pública' etc., de modo a enriquecer a doutrina ( $v$. Álvaro Lazzarini e outros, Direito administrativo da ordem pública, Rio de Janeiro, Forense, 1986). Não é necessário fazê-lo neste passo, basta resumir-lhe as liçōes, em face do texto em exame. Deste claramente resulta que segurança pública é a garantia da ordem pública, aqui distinguida da incolumidade da pessoa e do patrimônio. Já a ordem pública, neste passo, é a ausência de desordem, a paz, de que resultam a incolumidade da pessoa e do patrimônio." 7

Tenho entendido, ao certo, que "Falar sobre segurança pública exige do doutrinador cauteloso a atitude de sempre reportar-se à ordem pública, face à inter-relação existente entre esses conceitos. Igualmente a festejados administrativistas pátrios e europeus, entende que a segurança pública é um aspecto da ordem pública, concordo até que seja um dos seus elementos, formando a tríade ao lado da tranqüilidade pública e salubridade pública, como partes essenciais de algo composto. Saliento que não é uma ordem pública reduzida, como já se interpretou. (...) A ordem, assim como a segurança, são valores etéreos, de difícil aferição e não é por acaso que publicistas de renome mundial, sucessivamente, atravessaram séculos a estudálas, tal a complexidade que oferecem. Podem-se afirmar com certeza que a ordem pública é sempre efeito de uma realidade nacional que brota da convivência harmônica resultante do consenso entre a maioria dos homens comuns, variando no tempo e no espaço em função da própria história. $O$ arcabouço jurídico que o Estado proporciona à sociedade é simples trauutor dessa ordem. Evidentemente às elites intelectuais do país cabe papel importante, pois mercê de sua bagagem cultural pode e deve mostrar caminhos para a evolução dos componentes, que intelectuais do porte de Paul Bernard, Louis Rolland, Santi Romano, Marcel Waline, Blaise Knapp, entre outros, tão bem delinearam ao conceituar ordem pública, conforme traduzi no Direito Administrativo da Ordem Pública" .

A minha colocação do que seja segurança pública está restrita àquilo que Mário Pessoa diz ser 'o estado antidelitual, que resulta da observância dos preceitos tutelados pelos códigos penais comuns e pela lei das contravenções', com ações de polícia repressiva ou preventiva típica ('O Direito da Segurança Nacional' Biblioteca do Exército e Revista dos Tribunais/Editores, 1971, São Paulo, pp. 7 e ss.). Em outras palavras, e no dizer de De Plácido e Silva, 'segurança pública' é o afastamento,

7 FERREIRA FILHO, Manoel Gonçalves. Comentários à Constituiçäo Brasileira de 1988. v. 3, 1994, Editora Saraiva, Sāo Paulo, p. 82.

8 LAZZARINI, Álvaro. Estudos de Direito Administrativo. Coletânea Jurídica da Magistratura-2. Coordenação de Yussef Said Cahali e Sistematização do Rui Stoco. Escola Paulista da Magistratura/Editora Revista dos Tribunais. São Paulo, $1^{\mathfrak{a}}$ ed. e $2^{\mathrm{a}}$ tiragem, 1996. p. 76. 
por meio de organizações próprias, de todo perigo. ou de todo mal que possa afetar a ordem pública. em prejuízo da vida, da liberdade ou dos direitos de propriedade do cidadão, limitando as liberdades individuais, estabelecendo que a liberdade de cada cidadão, mesmo em fazer aquilo que a lei não lhe veda, não pode ir além da liberdade assegurada aos demais, ofendendo-a ('Vocabulário Jurídico', v. IV, $1^{\mathrm{a}}$ ed., 1963, Forense, verbete 'Segurança Pública', p. 1.417)" 9.

Para finalizar este tópico, anoto que o Senado Federal, pela sua Subsecretaria de Edições Técnicas, na edição de 1996 da Constituição da República Federativa do Brasil e conforme seu "Índice", em verbete nominado de Segurança Nacional, admite como sendo de tal matéria os seus artigos $91, \S 1^{\circ}$, incisivo III, 21 , inciso III, e artigo 22, inciso XXVIII, que cuidam sobre suas áreas, defesa, competência da União, defesa aeroespacial, marítima, civil e territorial, não fazendo, porém, nenhuma referência à hipótese do seu artigo 173 , justamente, o único que utiliza tal expressão.

\section{Responsabilidade de cada um dos Poderes da República na Defesa do Estado de Direito}

Poder Legislativo, Poder Executivo e Poder Judiciário, independentes e harmônicos entre si (artigo $2^{\underline{a}}$ da Constituição da República), evidentemente têm responsabilidade na defesa do Estado de Direito, porque, devem cuidar, dentro das respectivas competências constitucionais, dos objetivos fundamentais da República Federativa do Brasil na construção de uma sociedade livre, justa e solidária, devem garantir o desenvolvimento nacional, erradicar a pobreza e a marginalização e reduzir as desigualdades sociais e regionais, promovendo o bem de todos, sem preconceitos de origem, raça, sexo, cor, idade e quaisquer outras formas de discriminação, tudo a teor do artigo 3ำ, caput e incisos I a IV, da Constituição da República.

Ao certo o grande gerenciador de todos esses objetivos fundamentais, que têm reflexos na segurança nacional e/ou na segurança pública, é o Executivo, o qual, porém, para que possa desincumbir-se do seu munus estatal necessita estar amparado pelo Legislativo através de uma legislação adequada e razoável (princípio da razoabilidade), assentada na realidade brasileira (princípio da realidade), porque, só assim ela se tornará eficiente e eficaz para o Brasil, sem crise de constitucionalidade de leis ou atos normativos infralegais, como amiúde vem acontecendo, crises essas que acabam por ser gerenciadas pelo Judiciário na sua competência constitucional de dizer o Direito ao caso concreto litigioso, o que, ultimamente, não tem agradado o Executivo e/ou Legislativo, que acenam ameaças de seu controle externo, súmulas vinculantes, tetos e subtetos de vencimentos etc., tudo com apoio da mídia na formação da opinião pública contra o Judiciário, a pretexto de que suas decisões inviabilizam o Brasil, inclusive, em face de sua morosidade. 
E sobre o Poder Judiciário, também. jogam a responsabilidade pela falta de segurança pública, em especial nas comunidades rurais e urbanas do Brasil, porque, a Polícia prende e a Justiça solta ou. então, que os juízes brasileiros não estão atentos às crises sociais que assolam o país, em especial, na área da reforma agrária.

Não é, no entanto, o que ocorre, pelo menos no Estado de São Paulo, onde o seu Poder Judiciário, com cerca de 6.380 .482 processos - 516.529 criminais em abril de 1997 - em andamento" 10 distribuídos pelos seus só 1.293 juízes de $1^{\text {a }}$ Instância ou grau de jurisdição ${ }^{11}$, na defesa do verdadeiro Estado de Direito Estado Democrático de Direito na semântica constitucional vigente -, em verdade solta o acusado, somente, quando o trabalho policial não atende o desejável em termos de coleta de provas contra o acusado como exigido na legislação processual penal.

Segundo dados do Tribunal de Justiça do Estado de São Paulo (Corregedoria Assessoria da Presidência - Informática — Oficial PM de Ligação da Polícia Militar — Termo de Cooperação TJ/PMESP, em 30 de novembro de 1996, era de 118.263 o total de mandados de prisão a serem cumpridos, certo que, no período de 1992 a 1996, a ínfima média diária de cumprimento desses mandados de prisão era de $8,43 \%$, mesmo porque não há prisões adequadas para recolher os condenados, estando todas superlotadas e com rebeliões quase que diárias, conforme a mídia noticia.

Ao Poder judiciário, igualmente, não se pode imputar responsabilidade pela crise no campo, nas questões agrárias, porque, se um proprietário ou simples possuidor tiver as suas terras invadidas e ajuizar ação para reavê-las, ao certo o juiz da causa há de aplicar a regra do Direito vigente, segundo os fins sociais da lei e as exigências do bem comum (artigo $5^{0}$ da Lei de Introdução ao Código Civil Brasileiro), sob grave pena de, em prevaricando, não cumprir e fazer cumprir o ordenamento jurídico no seu munus estatal de dizer o direito ao caso concreto litigioso, com violação ao seu dever de "cumprir e fazer cumprir, com independência, serenidade e exatidão, as disposições legais e os atos de ofício" (artigo 35, inciso I, da Lei Orgânica da Magistratura Nacional, Lei Complementar n. 35, de 14 de março de 1979).

Mas, ao lado da Polícia Militar que, embora integre o Poder Executivo, é a ponta da linha nas questões de segurança pública e que tem no Poder Judiciário o seu ponto de chegada, as coisas não andam bem no Estado de São Paulo, principalmente após o encaminhamento, pelo Chefe do Poder Executivo Estadual, de uma Proposta de Anteprojeto de Emenda Constitucional que, a pretexto de uma nova Polícia, em verdade, quebra a moral policial militar de modo irreversível, com conseqüências graves na área de segurança pública e eventual reflexo na área da segurança nacional.

10 CORREGEDOIRA GERAL DA JUSTIÇA DO ESTADO DE SÃo PAUlO, Comunicação CG a.371/97. Movimento Judiciário de Primeira Instância. Mês de Referência: abril/97. Diário Oficial da Justiça, São Paulo. Caderno I - Parte I, 04 de junho de 1997, p. 2.

11 DEPARTAMENTO DA MAGISTRATURA - DEMA 2. Tribunal de Justiça do Estado de São Paulo, Rclação do nimero de cargos vagos e preenchidos na Magistratura do Estado de São Paulo, 02 de junho de 1997. 
Tal proposta, como afirme em Exposição à CPI - COMISSÃO PARLAMENTAR DE INQUÉRITO SOBRE FATOS OCORRIDOS COM POLICIAIS MILITARES EM DIADEMA-SP E PARA APURAÇÃO DAS RAZÕES QUE LEVAM AO CRESCIMENTO DA VIOLÊNCIA POLICIAL ${ }^{12}$, foi de uma violência única contra os policiais militares em geral e contra os sadios valores policiais militares, como o são o patriotismo, civismo, hierarquia, disciplina, profissionalismo, lealdade, constância, espirito de corpo, honra, dignidade, honestidade e coragem, violência essa que se tornou tanto pior quando quem irrogou as acusações foram justamente o Chefe Supremo da Polícia Militar do Estado de São Paulo e o seu Sub-Chefe, respectivamente Governador do Estado e Secretário da Segurança Pública (artigo 144 , § $6^{2}$, da Constituição da República, e artigo $139, \S 1^{\mathfrak{Q}}$, da Constituição do Estado), restando, portanto, indagar o que fizeram tão ilustres agentes políticos civis, que chefiam os dois ramos da Polícia Estadual, para que ela seja estável, eficaz e organizada?

O que fizeram foi estigmatizar todo policial militar ou civil paulista, acusando a Polícia Policia Civil de corrupta e a Polícia Militar de violenta, de modo que sendo policial civil, em princípio, deve-se presumir que é corrupto e sendo policial militar que é violento, quando, ao certo, no grande universo da Polícia Estadual, que é única, temos alguns poucos policias civis que a mídia diz serem corruptos e não uma Polícia Civil corrupta; temos, no mesmo diapasão, alguns policiais militares que a mídia diz serem violentos e não uma Polícia Militar violenta.

Não posso concordar com generalizações, como vem sendo generalizadas as acusações contra o aparato policial estadual, em especial em relação aos policiais militares, acusados pelo Governo de São Paulo de incapazes e inidôneos.

Insisto ser necessário que os governantes tenham vontade política para disciplinar a atuação policial, sendo este o grande papel das secretarias de segurança pública, ou seja, o secretário da segurança pública deve liderar a Polícia Estadual, deve ser o administrador da segurança pública de cada Estado e do Distrito Federal, porque, precisa ficar bem assentado, Polícia, como atividade jurídica do Estado, não pode ficar à mercê de quem não a conhecer e/ou, por aversão a ela, não faz questão de conhecê-la na profundidade que ela merece ser conhecida.

Já o afirmei e ora reafirmo que "não se deve misturar ressentimentos contra as Instituições Policiais Militares, por fatos do passado recente, com a problemática da segurança pública, conforme descreve o Professor Ney Prado, na obra 'Os Notáveis erros dos Notáveis'. Pela importância a segurança pública não pode ficar ao sabor de sentimentos menores, de argumentos emocionais, mas deve ser pensada com a máxima racionalidade" 13 .

12 LAZZARINI, Álvaro. Exposiçāo cit., em 08 de maio de 1997, p. 19. Ainda não publicada em repertórios.

13 LAZZARINI, Álvaro. A Segurança Pública e o Aperfeiçoamento da Polícia no Brasil, "Revista Forense". Editora Forense, Rio de Janeiro, 1991, v. 316, p. 3 e seguintes' Idem, "Revista de Direito Administrativo", Editora Renovar/Fundaçāo Getúlio Vargas, Rio de Janeiro, v. 184, p. 25-85: Idem, “Estudos", ed. e tiragem cits., p. 114. 
Lemb.o, de início, que o tema da violência e da segurança pública envolve. naturalmente, a Polícia, atividade jurídica do Estado, que deve ter seus problemas solucionados à luz das Ciências do Direito e da Administração Pública, certo que o conhecimento científico, abrangente de experiências diversas e sedimentado pelo tempo, representa caminho seguro na tomada de posições.

Limitar-me-ei à tentativa de solução sob o prisma da Polícia e da Justiça, aliás, como o fiz ao longo deste estudo, embora certo que trata de segurança pública no Brasil não é tarefa das mais fáceis, como tenho comprovado em mais de quarenta anos de estudos a ela dedicados.

Embora não falte ao Brasil mentes brilhantes voltadas para o assunto, tenho observado que, insistentemente, incorre-se no erro de tratar a segurança pública como algo restrito à questão policial e não de uma forma sistêmica.

Estudada a problemática com a amplitude necessária, isto é, desde as causas da criminalidade, passando pelo ciclo de polícia e concluindo com o ciclo da persecução criminal, com certeza chega-se à conclusão de que a Polícia, apesar das imperfeições, é o segmento que melhor funciona, justamente pela estabilidade advinda da organização das Polícias Militares, em verdade o esteio da segurança pública no Brasil.

É costume, entretanto, centrar-se na Polícia a culpa pela insegurança, exaltando-lhe os defeitos, que efetivamente existem, mas não são tão grandes a ponto de exigir mudanças radicais, sendo suficientes para corrigi-los algumas medidas de ajuste.

No âmbito da Polícia Estadual, em especial no referente à Polícia Militar, como política para solução dos problemas, tenho defendido, de modo intransigente, o estrito cumprimento da lei, pois, não me agradam idéias de confronto pelo confronto, não me agradam propostas traumáticas.

Daí por que, a exemplo do que o fiz na monografia "Segurança Pública e o Aperfeiçoamento da Polícia no Brasil", coerente com a minha linha de pensamento, ofereço, em seguida, contribuição para a tentativa de solução do problema da violência e segurança pública no Brasil e, inclusive, nos seus grandes centros urbanos.

Minhas propostas são para que, com a máxima urgência:

a) haja uma razoável Política Nacional de Segurança Pública, que atenda a realidade brasileira, constituída de inúmeras realidades regionais;

b) seja cumprida a norma do artigo 144 , parágrafo $7^{\mathfrak{0}}$, da Constituição da República, pois, passados mais de oito anos de sua vigência, o Congresso Nacional ainda não cuidou da lei que deve disciplinar a organização e o funcionamento dos órgãos responsáveis pela segurança pública, de maneira a garantir a eficiência de suas atividades; e

c) numa segunda etapa, devem vir as demais leis necessárias para os fins colimados pela norma constitucional indicada na alínea anterior.

Para tanto, considero pressupostos básicos na orientação dos trabalhos:

a) o relacionamento harmônico entre os órgãos encarregados da segurança pública, inclusive guardas municipais e seguranças privadas; 
b) a observação do princípio da racionalidade, eliminando-se, de vez, a superposição de funções. através da diminuição drástica das áreas de interseção de competências;

c) a melhoria da eficiência e aproximação dos órgãos policiais, mediante evolução constante do ensino policial, voltado para atividades específicas de cada órgão, além dos necessários ajustes na estrutura administrativa;

d) moralização da Polícia, dando-se enfase a uma deontologia policial e, assim, combatendo-se a violência, a corrupção e o desvio de finalidade na atividade policial, que são as principais questões éticas da polícia;

e) valorização do policial, inclusive com previsão de pena mais exacerbada quando a vítima do marginal é policial ou familiar seu, em especial, nos casos de vingança; $\mathrm{e}$

f) que o modelo, em linhas gerais, deva valer para todo o País.

Para a harmonia entre os órgãos policiais, tenho como pressuposto o seguinte:

a) todo e qualquer órgão federal destinado a administrar, em nível nacional, a segurança pública deve ter uma participação paritária dos órgãos policiais, incluindo representantes dos Ministérios interessados;

b) a existência de Secretaria de Segurança Pública em todos os Estados e Distrito Federal - e Territórios quando houver — destinada a:

- coordenar as atividades policiais na respectiva entidade federada, zelando para que os órgãos policiais voltem-se ao cumprimento de suas atribuições constitucionais;

- administrar de forma centralizada a identificação civil, as informações criminais e sobre armas e veículos, permitindo a utilização de tais dados pelas duas Polícias;

- regulamentar as situações em que se fizer necessário o apoio de uma Polícia à outra. Para tanto a Secretaria de Segurança Pública deverá ser necessariamente composta por integrantes das Polícias Civil e Militar, paritariamente;

c) vinculação das guardas municipais às Polícias Militares para efeito de adestramento e controle; $\mathrm{e}$

d) regulamentação das seguranças privadas, definindo a competência das Polícias Militares na fiscalização quanto ao uso de uniforme, que não poderá confundir-se com uniforme militar, armamento e equipamento, isso independentemente da competência de outros órgãos policiais.

Há, também, a necessidade de medidas para restrição das áreas de interseção de competências entre as Polícias Civil e Militar. As medidas devem buscar:

a) detalhamento das atribuições mediante lei; lei;

b) definição das áreas limítrofes de competência através da regulamentação da

c) competência da Polícia Militar na prevenção mais a repressão imediata, restrita às ações de força, coleta inicial de provas e preservação de locais de crime, não the cabendo atuar na investigação de crime, ou seja, ao que se denomina de "terceira fase do ciclo de polícia": e

d) competência da Polícia Civil para a repressão mediata, através das investigações, incluída a polícia-técnico-científica. Não lhe cabe a prevenção criminal. isto 
é. a denominada "primeira fase do ciclo de polícia" e, menos ainda. a denominada "repressão imediata".

Tais medidas propostas têm em vista o aperfeiçoamento da produção da prova e consequientemente a redução da impunidade, razão de assim exemplificar-se em seguida:

- ocorrendo a infração penal de menor potencial ofensivo, o policial militar que atender a ocorrência tomará as medidas de força necessárias e colherá as provas, encaminhando após o caso ao Juizado Especial ou à Polícia Civil;

— nas demais infrações penais a policial militar que atender a ocorrência, tomará as medidas de força necessárias, procederá a coleta inicial das provas e preservará o local até a chegada da Polícia Civil, que, a partir daí, ficará encarregada do caso.

A legislação, também, deverá cuidar de outras situações que a realidade mostra que devem ser objeto de regulamentação.

Para uma melhor aproximação e maior eficiência das Polícias Civil e Militar no combate à violência e assim à criminalidade, tem sido minha proposta o seguinte:

a) hierarquização vertical da Polícia Civil, nos moldes da Polícia Militar;

b) estabelecimento, como consequiência da hierarquização, de correspondência entre os cargos nas Polícias Civil e Militar;

c) padronização e integração dos Boletins de Ocorrência (BO) das Polícias Civil e Militar, quando se tratar de infração penal;

d) interligação maior entre os seus serviços de comunicação;

e) aperfeiçoamento e aproximação do ensino, mediante:

- compatibilização dos currículos escolares;

- especialização nas atribuições específicas de caga órgão, sem prejuízo da cultura geral;

- aumento da carga horária de ensino;

- incentivo às disciplinas voltadas contra a violência, a corrupção e o desvio de finalidade na atividade policial, com especial ênfase para a deontologia policial.

No que se refere às medidas moralizadoras da Polícia, minha proposta é:

a) padronização da Lei Disciplinar das Polícias Civil e Militar, mantendo capítulo específico para as transgressões tipicamente militares.

b) padronização da identidade funcional; e

c) aquelas previstas em relação ao ensino.

Quanto à persecução criminal, além de outras medidas legislativas que desburocratizem o processo penal, entende que urge:

a) a criação e a instalação dos Juizados Especiais de que trata o artigo 98, inciso I, da Constituição da República; e

b) a criação e instalação dos Juizados de Instrução.

Aponto, igualmente, a questão do Sistema Prisional, sugerindo a municipalização de sua estrutura, e não a sua privatização como alguns querem, dentro do esforço para reintegrar o preso ao convívio social. Essa medida pode ser viabilizada através de convênios. Os municípios, assim, ficarão encarregados primordialmente dos programas sociais, preventivos das causas da criminalidade, como também da complementação da tarefa. pois, cabe com maior propriedade à comunidade local, próxima que está, providenciar o retorno do preso ao seu meio social. 
A Polícia, de qualquer modo, deve retirar-se da rede prisional, aliás, conforme concluiu estudo apresentado no Ciclo de Seminários Sobre Ações Governamentais - Segurança Pública ${ }^{14}$

Por derradeiro, insisto que as medidas propostas não devem ser avaliadas isoladamente, mas pelo conjunto que representam. Dessa visão maior, por certo, dependerá sua efetividade, em benefício do controle da violência e da criminalidade das grandes cidades, principalmente nas megalópolis, amenizando, assim, a insegurança da comunidade.

\section{Conclusão}

Passo concluir, ao contrário do que ocorre com a segurança pública que têm tratamento constitucional no artigo 144 da Constituição da República, inclusive no que diz respeito ao seu conceito e órgãos que integram o sistema de segurança pública com suas competências, a temática da segurança nacional não teve o mesmo tratamento, embora esteja implícito em várias normas constitucionais vigentes cuidarem elas de questões de segurança nacional, expressão essa usada uma vez no artigo 73, caput, da Constituição da República, mas só no que pertine à "Ordem Econômica e Financeira".

A segurança pública, enfatizo, tem papel preponderante na realização da segurança nacional, porque, é uma necessidade básica de qualquer pessoa de sentir-se com segurança e bem-estar. Seguro, o homem pode trabalhar melhor, implicando a ordem, no progresso do Estado Brasileiro.

Urge, bem por isso, que todos os Poderes do Estado de Direito, embora independentes e harmônicos entre si, fiquem sensibilizados e, dentro de suas competências constitucionais, encontrem um ponto de equilíbrio social que, naturalmente, será baixado por uma legislação social justa na busca do bem comum.

Há necessidade de os Poderes Executivo e Legislativo Federal darem cumprimento ao comando do artigo $144, \S 7^{\circ}$, da Constituição da República, disciplinando a organização e o funcionamento dos órgãos responsáveis pela segurança pública, de maneira a garantir a eficiência de suas atividades.

Necessário, também, é que sejam deixados de lado os ressentimentos e preconceitos contra militares que tem considerável parcela da sociedade brasileira, alimentada por pessoas que se opuseram ao denominado "regime militar de 1964", agora, apoiados por órgãos de comunicação social.

14 Fundação do Desenvolvimento Administrativo - FUNDAP. Cabo de Seminários Sobre Açōes Governamentais - Segurança Pública. Anais. São Paulo. 26/27 de janeiro de 1987. p.10. 


\section{A FRAUDE}

À LEI

REGIS FKIINY R PIRIIKA

Ref. 0065

Brochura

142 págs.

FENOVAR

Form. $14 \times 21$

1994

\section{A FRAUDE \\ À LEI}

Regis Fichtner Pereira

O tema tratado neste livro é de grande relevância e atualidade. Trata-se de figura jurídica componente da chamada Teoria Geral do Direito, de aplicação a todos os ramos da ciência jurídica. A fraude à lei é tratada de forma sistemática, sem que o autor tenha se prendido a determinado ramo do Direito. $\mathrm{O}$ estudo foi elaborado com amplitude e dentro de parâmetros científicos, suficientes a auxiliar o intérprete e aplicador da lei na solução de questōes jurídicas em que ocorra a violação indireta da norma jurídica. 